\title{
Psychological hesitance and myths related to COVID-19 vaccine is a hindrance in vaccination process in Pakistan
}

\author{
NOOR AIN ${ }^{1}$, Noor -Ul-Ain ${ }^{2}$, and Saleeha Sajjad ${ }^{3,4}$ \\ ${ }^{1}$ Affiliation not available \\ ${ }^{2}$ Department of pharmacy, The University of Faisalabad \\ ${ }^{3}$ Department of pharmacy, Department of Pharmacy, The University of Faisalabad \\ ${ }^{4}$ The University of Faisalabad
}

May 14, 2021

\begin{abstract}
The entire world is dealing with this pandemic of COVID-19 since December 2019. And several variants of this SARS-COV2 virus have occurred and they have more impact on the increase in the mortality rate and it has now increased to more than 5 percent up till now which is quite an alarming state. But despite this, every day increasing mortality rate the vaccine which is now available for use is not considered to be effective by the general population due to their self-created myths and this leads them to be reluctant to the vaccine. And that's why the vaccination process is still far slow as we know that the number of cases is getting increased day by day the immunization by the vaccine is much important to cope up with this challenging pandemic. There is a need to avoid the psychological considerations for the vaccination because vaccine provision is important to provide the maximum number of individuals with the vaccine so the more complex states of this variant form of viral infection could be deal with in a more sophisticated manner.
\end{abstract}

\section{Hosted file}

covid19-converted.pdf available at https://authorea.com/users/346729/articles/521988psychological-hesitance-and-myths-related-to-covid-19-vaccine-is-a-hindrance-invaccination-process-in-pakistan 